\title{
PROPOSTA DE IMPLEMENTAÇÃO DO MÉTODO 8S NO SETOR DE RECURSOS HUMANOS: ESTUDO DE CASO NA IMPERLAVE COMÉRCIO E SERVIÇOS DE MÓVEIS
}

\section{ARTIGO ORIGINAL}

MACEDO, Luciane Duarte ${ }^{1}$, ROCHA, Bruna de Menezes², AVINTE, Maria Daniele da Silva ${ }^{3}$, ALMEIDA, Victor da Silva ${ }^{4}$, SANTOS JÚNIOR, Aldemir Pereira dos ${ }^{5}$, ROBERTO, José Carlos Alves ${ }^{6}$

MACEDO, Luciane Duarte. Et al. Proposta de implementação do método 85 no setor de recursos humanos: estudo de caso na Imperlave Comércio e Serviços de Móveis. Revista Científica Multidisciplinar Núcleo do Conhecimento. Ano. 06, Ed. 11, Vol. 14, pp. 158-181. Novembro de 2021. ISSN: 2448-0959, Link de acesso: https://www.nucleodoconhecimento.com.br/administracao/metodo-8s,

DOI:

10.32749/nucleodoconhecimento.com.br/administracao/metodo-8s

\section{RESUMO}

O referido artigo propõe um estudo de caso centrado na empresa Imperlave Comércio e Serviços de Móveis - EIRELLI, sendo esta de pequeno porte, operando neste segmento de atuação, com ênfase na prestação de serviços. Por intermédio do Diagnóstico Organizacional, destaca-se que a área de Recursos Humanos da instituição encontra-se com mais baixa classificação e envolta em demasiadas falhas. Neste contexto, o presente artigo, tem como questão norteadora: como a implementação do programa $8 \mathrm{~S}$ na empresa Imperlave pode contribuir com as

\footnotetext{
${ }^{1}$ Graduanda do curso de Administração.

${ }^{2}$ Graduanda do curso de Administração.

${ }^{3}$ Graduanda do curso de Administração.

${ }^{4}$ Coorientador. Mestre em Engenharia de Processos. Pós-Graduando em Neuropsicopedagogia Institucional. Especialista em Gestão Estratégica de RH. Graduado em Administração e Pedagogia.

${ }^{5}$ Coorientador. Mestre em Ciências do Ambiente e Sustentabilidade na Amazônia. Especialista em Gestão dos Recursos Naturais e Meio Ambiente. Especialista em Metodologia do Ensino Superior. Graduado em Turismo e Administração.

${ }^{6}$ Orientador. Mestrado profissional em Engenharia de produção. Especialização em Gestão em Logística empresarial. Graduação em Administração com Ênfase em Marketing.
} 
melhorias contínuas na área de recursos humanos? Para possibilitar a resolução deste questionamento, apresenta-se o objetivo geral, que é delinear a efetivação do método $8 \mathrm{~S}$ na gestão de Recursos Humanos da empresa Imperlave. Quanto à metodologia, este trabalho possui abordagem qualitativa, bem como natureza exploratória e bibliográfica. Visa-se a utilização da ferramenta $5 \mathrm{~W} 2 \mathrm{H}$ como instrumento para introdução das ações propostas, proporcionando maior assertividade e segurança na condução dos trabalhos. Os Recursos Humanos $(\mathrm{RH})$ buscam, desde seu desenvolvimento em meados dos anos 70 e 80, a fiel coordenação de toda a capacidade colaborativa, visando-se que estes envolvidos mantenham-se capacitados e motivados. Deste modo, introduz-se as ações propostas por meio dos censos colaborativos na Imperlave, pois a ferramenta apontou para uma melhor evolução em todos os envolvidos com o desenvolvimento da corporação.

Palavras-chave: Diagnóstico, $\mathrm{RH}$, Ferramenta, 5W2H.

\section{INTRODUÇÃO}

Com os ambientes corporativos tornando-se cada vez mais complexos e competitivos, as instituições necessitam renovar-se com uma frequência crescente. Isto é necessário para possuir vantagem sobre seus concorrentes, o que implica a busca por soluções para adversidades do cotidiano corporativo de maneira constante. Sendo assim, constitui-se o referido artigo como um estudo de caso aplicado à empresa Imperlave Comércio e Serviços de Móveis - EIRELLI, classificada como empresa de pequeno porte, cujas atividades efetuadas voltam-se ao ramo de prestação de serviços. A instituição submeteu-se a verificações aclaradas pelo diagnóstico empresarial. Compreende-se que o referido setor de Recursos Humanos se destacou como o de menor classificação no gráfico das áreas funcionais. Assim, ocorre a necessidade de desenvolver de forma saudável os relacionamentos internos. Em busca desta premissa, o objetivo geral estabelece-se em delinear a efetivação do método $8 S$ na gestão de Recursos Humanos da empresa Imperlave. 
Conforme Severino (2013, p. 113), estabelecer o problema de pesquisa "[...] trata-se, portanto, de delimitar, circunscrever o tema problema. O tema deve ser problematizado e é preciso ter uma ideia muito clara do problema a ser resolvido". Mediante o exposto pelo autor, a conclusão dos objetivos tornou-se possível, pois indagou-se e estabeleceu-se o seguinte questionamento: Como a implementação do programa 8S na empresa Imperlave pode contribuir com as melhorias contínuas na área de Recursos Humanos? Percebe-se a necessidade deste departamento ser aperfeiçoado, como apontam os estudos que abordam sobre o tema, no entanto, apresenta-se a seguir um estudo de caso que deseja incorporar técnicas de gestão como as ferramentas $8 \mathrm{~S}$ e Kaizen a este âmbito específico. $\mathrm{O}$ estudo assume características de uma pesquisa qualitativa, exploratória e bibliográfica, cujo intuito é definir as ações necessárias, tendo como base a ferramenta $5 \mathrm{~W} 2 \mathrm{H}$.

A partir do XX, propôs-se um novo conceito organizacional. Este visa à mudança nos relacionamentos internos. Desde então, formula-se o setor de Recursos Humanos. Atualmente, este campo é responsável por gerir o corpo produtivo da empresa, isto desde a inclusão ao desligamento. Viabiliza-se sua concretização conforme os objetivos específicos de: detalhar a metodologia e seus benefícios à gestão organizacional; analisar os processos que podem ser submetidos à esta; e propor ações introdutórias aos resultados obtidos por meio do método. Ao setor de Recursos Humanos é incumbido o dever de agregar valor ao corpo operacional para, assim, proporcionar um relacionamento intrínseco com a corporação. Este visa fortalecer as conexões entre os graus hierárquicos. Portanto, mediante as análises realizadas nas esferas institucionais, espera-se que, com as ações propostas, o gerenciamento dos colaboradores se torne eficaz, transcrevendo-se em adesão de métodos corretos de abordagem aos clientes, porém, incorporando valor aos demais setores, bem como objetiva-se o alavancamento das finanças da instituição.

\section{FUNDAMENTAÇÃO TEÓRICA}

Garcia (2016, p. 292), assevera que "a revisão bibliográfica, confundida muitas vezes com a pesquisa bibliográfica, é uma parte muito importante de toda e qualquer 
pesquisa, pois é a fundamentação teórica, o estado da arte do assunto que está sendo pesquisado [...]". Praça (2015, p. 74), por sua vez, afirma que "deve sempre ser realizado baseado em técnicas específicas operacionais interligadas, ou seja, o método científico está baseado em um conjunto de etapas realizadas através de técnicas bem definidas [...]".

\subsection{CONCEITO DE RECURSOS HUMANOS}

O gerenciamento de recursos humanos é uma modalidade que se apresenta desde os primórdios da humanidade. No entanto, foi apenas entre as décadas de 70 e 80, nos Estados Unidos, que o conceito surgiu como ideal de ciência. De acordo com Santos e Demambro (2021), conceitua-se o setor como o que busca a implementação de diversas concepções planejadamente específicas. O foco, como o próprio nome o descreve, é o capital humano e tudo que busca motivá-lo e capacitá-lo. Deste modo, compreende-se que este almeja proporcionar aperfeiçoamentos constantes ao corpo trabalhista da organização. Cardoso (2012, p. 03), salienta que o campo dos recursos humanos "[...] não é algo que se limita a apenas um departamento, mas que se difunde por toda a organização já que não existem especialistas, sendo uma função exercida por todos os colaboradores [...]".

\subsubsection{GERENCIAMENTO DE PESSOAS}

Anteriormente, a realidade do campo dos Recursos Humanos tem desmistificado uma compreensão que destacava que o Departamento Pessoal era unicamente responsável por admitir e demitir colaboradores. Cardoso (2012, p. 03), afirma que "a gestão de recursos humanos é um processo organizacional complexo, podendose definir muitas vezes como de gestão de pessoal e/ou função de recursos humanos [...]". No entanto, conforme Chiavenato (2014), nas últimas décadas, com a atualização e desenvolvimento dos instrumentos que auxiliam os processos produtivos, o crescimento de capital humano, hoje, é uma recorrência iminente, pois transforma tudo em diferencial competitivo. 
O autor completa que ao buscar utilizar todas as competências que os colaboradores possuem, o pensamento foi transformado nas empresas. Passou-se a investir no capital humano, o qual, corretamente gerenciado, desenvolve melhores produtos e serviços, contudo, não foca somente na produção dos bens e serviços.

\subsubsection{CONCEITO DE 8S}

A ferramenta foi desenvolvida a partir da junção do eixo dos $5 \mathrm{~s}$ já existente no Japão. Contudo, outras nações adequaram e implementaram a metodologia no ocidente. Mizdal (2017, p. 12), entende que "a implementação da ferramenta $8 S$ tem como objetivo principal a reestruturação completa da empresa a partir dos recursos humanos, visando melhorar a produtividade por meio da organização, combatendo os desperdícios". Ferreira (2013), afirma que, corretamente administrados nas corporações, os recursos humanos proporcionam melhorias contínuas no convívio e na sistematização entre os públicos ao amparar-se nos 5 sensos: utilização; organização; limpeza; padronização; e disciplina. Devem ser colocados em prática com: determinação; educação/treinamento; e economia/combate aos desperdícios. A partir disso, as vantagens demonstram-se constantes no dia a dia da empresa.

\subsubsection{REDUÇÃO DE CUSTOS OPERACIONAIS}

Seja qual for o ramo mercante, este necessita de planejamento e avaliações relacionadas ao seu desempenho e economia, de modo que, conforme o segmento da atividade corporativa, as variáveis devem ser seriamente incorporadas para não haver erros ou falhas posteriores. O cálculo de custos das operações compreende tanto despesas indiretas como diretas, associadas a custos fixos e flexíveis. Determinações acerca da qualidade do produto ou serviço, bem como aquelas relacionadas à agilidade da entrega, são variáveis que devem sempre serem consideradas por um responsável logístico. Em todo mercado, a intenção sempre é a produção de lucros com a menor utilização de capital possível. Por vezes, para alcançar estas condições, simples ajustes efetuados sabiamente expressam resultados satisfatórios. 
Alguns exemplos de métodos destacam-se, como: mapear os processos para identificar gargalos; aproveitar ao máximo as atribuições dos colaboradores; mercar sabiamente com os fornecedores; buscar metodologias e tecnologias que abordem e aumentem a eficiência; planejar com base nos conceitos de melhoria contínua; e estabelecer metas reais e condizentes com a realidade financeira e estrutural da organização. Segundo Reis et al. (2018), um método reconhecido como forte auxiliador no desenvolvimento de lucro corporativo é a sábia utilização da inovação como ferramenta de gestão. Sendo corretamente aplicada, a inserção de maquinários, sistemas operacionais e metodologias estratégicas despertam fortes reduções nos custos individuais da produção, traduzindo-se em um maior aproveitamento do potencial produtivo, elevando-se a excelência dos itens.

Feijó e Behr (2016) denotam a sapiente gestão de custo e apontam que esta requer consciência no gerenciamento, cujas decisões devem ser tomadas de forma correlacionada aos custos diretos e indiretos, proporcionando, assim, real visualização dos custos, possibilitando a execução dos mesmos processos, porém, com redução de instrumentos e finanças.

\subsubsection{OBJETIVOS E VALORES, E SUA IMPORTÂNCIA NA ORGANIZAÇÃO}

Objetivo é o estímulo quanto ao alcance das metas. O foco ou alvo permitem que a empresa possa alcançar suas ambições. No âmbito empresarial, o conceito não difere, pois, assim como os indivíduos, as corporações sempre almejam metas e buscam renovar-se constantemente. Quanto aos valores, são conglomerados de atributos de indivíduos ou entidades, sejam elas públicas ou privadas. Esses, quando estabelecidos, devem ser seguidos internamente, pois declaram o comportamento esperado e ditam a maneira de se relacionar mutuamente em sociedade. Sem conhecimento, ou correta adequação aos termos e procedimentos internos, o colaborador não estará ajustado ao que a empresa busca e, em consequência, estes não irão almejar as mesmas realizações. Portanto, a clareza dos objetivos e valores organizacionais são essenciais no relacionamento entre 
colaborador e empresa. Permitem o alcance mútuo das metas e a realização conjunta, transcendendo limites.

Atualmente, diante do exposto, nota-se que os gestores têm se concentrado em proporcionar aos colaboradores um maior autoconhecimento acerca de seus preceitos e de sua individualidade, de modo que estes demonstrem sua criticidade e criatividade na busca por soluções para as problemáticas identificadas no cotidiano. Neste sentido, Ferreira (2016, p. 35) afirma que "para compreender os conceitos de identidade social, organizacional, faz-se necessário, inicialmente, compreender a identidade pessoal [...]". Entretanto, Bedani (2012, p. 152) aborda que "[...] conjectura-se que a influência da cultura organizacional na criatividade e inovação ocorreria por intermédio de seus elementos constitutivos (pressupostos, valores e crenças) e de dois modos distintos".

\subsubsection{IMPACTO DO ATENDIMENTO E A IMPORTÂNCIA DA PADRONIZAÇÃO}

Atualmente, independentemente do ramo de atuação, com a modificação do pensamento dos consumidores, que se tornaram mais exigentes e críticos quanto ao que desejam, passou-se a existir um consenso de compreensão sobre o que gera satisfação entre os clientes, bem como sobre o seu desejo de retorno. Aceita-se que houve uma mudança em virtude da agregação de valores aos produtos ou serviços desenvolvidos pela instituição. Porém, muitas instituições não sabem como aplicar os devidos valores aos seus serviços, portanto, para Simoni (2016), a satisfação é companheira da qualidade.

Esta é desenvolvida por meio da concentração nos procedimentos. Conforme Veras et al. (2012), deslindar as necessidades dos clientes é o maior propósito do atendimento de excelência. $O$ intuito central desta metodologia é desenvolver benefícios sobre a concorrência e proporcionar um relacionamento mais íntimo com o consumidor. Já Teixeira et al. (2014) destacam que a competitividade é intensificada conforme a padronização e a qualidade. Segundo os autores, salienta- 
se que na gestão da qualidade a padronização dos processos é uma das questões de maior importância, pois esta visa desenvolver a constância entre os serviços internos e o que é apresentado aos clientes, produzindo certa antecipação quanto aos resultados.

\subsection{MÉTODO KAIZEN}

Hodiernamente, o conceito é bastante reconhecido e recorre-se a este para proporcionar melhorias contínuas nas instituições, porém, seu desenvolvimento ocorreu em meados do segundo período do século $\mathrm{XX}$, mais especificamente entre os anos 1950. Mediante ao concebido neste período, Dias et al. (2020) declaram que se conceitua Kaizen como agrupamentos de metodologias que, quando aplicadas na instituição, gerenciam melhorias relacionadas aos rendimentos, afinal, a essência da metodologia é proporcionar melhorias aos colaboradores para que estes, no que lhes concerne, tirem melhores proveitos.

De acordo com Loureiro (2018), a perspectiva do método objetiva o desenvolvimento continuado em todos os setores, valendo-se da circunspeção e ajuste econômico, abordando o encorajamento e a inventividade de todos os envolvidos nos processos produtivos, sempre encorajando a melhoria das práticas produtivas.

\subsubsection{MELHORIA CONTÍNUA COM KAIZEN}

Como se compreende, o conceito de Kaizen significa melhoria, aprimorar perenemente tudo ao seu redor, independentemente da área específica. Assim sendo, deseja proporcionar o melhor desenvolvimento no dia a dia, abordando todos os ambientes que envolvem o convívio das pessoas, seja em casa ou no trabalho. A autora Loureiro (2018) declara que o Kaizen deve abordar o pensamento de todos na organização, desde o nível estratégico até o operacional. Isso quer dizer que todos devem efetuar autorreflexões e buscarem por métodos de melhoria. Estas análises devem ocorrer inicialmente no íntimo de cada colaborador sendo, em seguida, expressas externamente. Tal conceito impulsiona a aplicação de atividades voltadas a proveitos na organização. 
Contudo, Casarin (2012) expõe que a melhoria contínua deve ser operacionalizada diariamente, isto é, deve ser desenvolvida de maneira gradual, para que, consecutivamente, os resultados desejados sejam alcançados. À medida em que a metodologia cria forma internamente, as problemáticas são avistadas e suas causas sanadas e, ao decorrer da aplicação, ocorre a normalização dos processos e garante-se a correta desenvoltura dos objetivos.

\subsubsection{BENEFÍCIOS E INCENTIVOS COMO MEIO DE MOTIVAÇÃO}

Com o desenvolvimento da humanidade, nota-se que, em razão de tais avanços históricos, o corpo trabalhista tornou-se mais suscetível à competitividade traçada entre as corporações. Desta maneira, Carvalho et al. (2013) afirmam que, ao decorrer da Revolução Industrial, o foco nas organizações transformou-se do produzir a quem produz. Deste modo, o assalariado tornou-se o centro de todo desenvolvimento das ações, cujas competências unificaram-se com a satisfação e empenho. Portanto, definiram-se benefícios e incentivos como fatores de estímulos que, aplicados e alcançados pelos funcionários de uma empresa, refletem na melhora do desempenho, tanto da instituição quanto do colaborador. A intenção principal é motivá-los por meio de recompensas por terem suas metas atingidas, apontando sempre os objetivos de cada um.

Com o desenvolvimento da era da informação no início dos anos 90, o centro do pensamento tornou-se o debate sobre as mudanças, pois as transformações ocorreram de forma imprevisível. O único guia era a progressão da tecnologia. Neste ambiente, o mercado busca rapidez, pensamento inovador e adaptabilidades frente às constantes transformações do meio empresarial. Com este pensamento transformador, a gestão de pessoas começou a transformar-se em termos conceituais, entendendo-se que os colaboradores não são apenas meios para alcançar os fins, pois, na verdade, estes possuem competências específicas e individualidade. Neste contexto, Silva; Fernandes e Dandaro (2013) idealizam que a necessidade pessoal é o que gerencia a motivação. Somente por meio desta que o 
indivíduo passa a compreender que precisa agir. Quanto mais urgente for a necessidade, maior esta ação será.

Os autores salientam que, no mundo corporativo, motivar os funcionários tornou-se o centro do gerenciamento, isto em decorrência da motivação em produzir melhores frutos.

\subsubsection{A IMPORTÂNCIA DE INSERIR E MANTER OS MÉTODOS DE MELHORIA CONTÍNUA}

O método $8 S$ envolve todos da organização e proporciona autoavaliação que acarreta correção; já o Kaizen busca a melhoria contínua, sendo este aplicado em setores como o de Recursos Humanos, pois promove reformulações necessárias à fluidez de todos os processos, bem como de todos envolvidos. Estas metodologias aplicadas sem falhas buscam encontrar os erros e gerir ações corretivas, de modo que as atividades sejam mais bem administradas e as falhas não ocorram mais, tendo, como consequência, o aumento da qualidade produtiva. Segundo Tanaka, Muniz Jr e Faria Neto (2012), o conceito de melhoria contínua deve ser abordado constantemente e todos os envolvidos, desde a gestão até as operações mais simples, devem fazer sua parte diariamente.

É necessário para que a elevação dos procedimentos ocorra e, para que a instituição conquiste vantagem sobre seus concorrentes, é necessário que os aspectos de inovação e desenvoltura trabalhista sejam bem manuseados para que a empresa seja afetada positivamente com tais melhorias. A aplicabilidade destas metodologias por si só, sem a permanência dos conceitos, não garante a efetividade. No entanto, ao unificar os conceitos e correlacionar processos, no intuito de efetuá-los com melhorias contínuas e máxima qualidade, garante-se a excelência dos itens ou serviços finalizados. Vieira et al. (2013) salientam que os processos e serviços devem transformar-se de maneira positiva diariamente, sendo que cada dificuldade deve ser ultrapassada, de modo que os erros se transformem em oportunidades de crescimento. 


\section{MATERIAIS E MÉTODOS}

$\mathrm{Na}$ busca por conhecimento, profissional ou acadêmico, para se avultar perspectivas, existem bases a partir das quais os indivíduos devem agarrar-se para melhor desenvolvimento. Logo, segundo Terra e Libório (2015, p. 15): "O método científico pode ser definido como um conjunto de regras básicas empregadas em uma investigação científica, com o objetivo de obter resultados, de forma imparcial e confiável [...]".

\subsection{PROCEDIMENTOS METODOLÓGICOS}

Conforme Severino (2013), deve-se compreender que, na atualidade, o âmbito das ciências naturais e humanas possui técnicas e métodos que devem ser aplicados aos elementos gerais de uma determinada área, pois, estando estes reunidos, desencadeiam toda a rede de conhecimento.

\subsubsection{QUANTO À NATUREZA}

Souza e Kerbauy (2017, p. 31) concebem que na pesquisa "[...] quantitativa o fenômeno da realidade social independe do pesquisador, na qualitativa o dualismo sujeito-objeto é aceitável, pois a realidade se relaciona com a mente do sujeito [...]".

Em concordância, Proetti (2018) ressalta que a pesquisa qualitativa visa adquirir explicações verídicas para aclarar e compreender os acontecimentos em estudo. Este estilo de abordagem possibilita uma conexão direta entre o pesquisador com seu objeto de estudo.

No que concerne à pesquisa quantitativa, está se desenvolve conforme delineação anteriormente estabelecida, guiando-se por variáveis e hipóteses. Portanto, nesta pesquisa, adotou-se o método de pesquisa qualitativa para melhor atender aos requisitos de análise profunda acerca dos obstáculos encontrados na instituição foco. 


\subsubsection{QUANTO AOS FINS}

Conforme Praça (2015, p. 75), a pesquisa exploratória "busca se familiarizar com os fenômenos surgidos durante a pesquisa, explorando os próximos passos mais profundamente e com maior precisão [...]".

Segundo Severino (2013, p. 107), aborda-se que "a pesquisa exploratória busca apenas levantar informações sobre um determinado objeto, delimitando assim um campo de trabalho, mapeando as condições de manifestação desse objeto [...]".

Uniformemente, utilizou-se da pesquisa exploratória para elaboração desta obra, com o intuito principal de descrever as problemáticas e buscar resoluções palpáveis a estas.

\subsubsection{QUANTO AOS MEIOS}

Garcia (2016, p. 292) aborda que "toda pesquisa, qualquer que seja seu delineamento ou classificação em termos metodológicos, deverá ter a revisão bibliográfica $[\ldots] "$.

De acordo com Severino (2013, p. 106), "a pesquisa bibliográfica é aquela que se realiza a partir do registro disponível, decorrente de pesquisas anteriores [...] Utilizase de dados [...] já trabalhados por outros pesquisadores e devidamente registrados $[\ldots] "$.

Conforme a descrição dos autores, nesta pesquisa, reuniram-se e categorizaram-se dados que têm como base a pesquisa bibliográfica.

\subsection{CARACTERIZAÇÃO DA EMPRESA}

A organização foco desta pesquisa, que foi desenvolvida em uma fase única, possui o registro de empresa com o nome de Imperlave Comércio e Serviços de Móveis - 
EIRELLI, já o nome fantasia é registrado como Imperlave. Encontra-se endereçada na Avenida Marques da Vila Real da Praia Grande, №: 07, Parque das Laranjeiras Flores, em Manaus, no estado do Amazonas, cujo CEP é 69058-100.

Esta empresa integra o Terceiro Setor do mercado, atuante no ramo da prestação de serviços de higienização e impermeabilização de estofamentos, em geral. O desejo de empreender neste ramo ocorreu quando seus atuais gestores visualizaram a forte necessidade de mercado especializado neste setor, então, no ano de 2011, colocaram a ideia em prática, surgindo, assim, a Imperlave.

Atualmente, o quadro de colaboradores é composto por cerca de 40 funcionários e a instituição atende várias empresas, em diversos ramos do comércio, dentre eles: fábricas, hotéis, lojas de decoração, lojas de móveis e muitos outros. Pioneira em técnicas específicas e aperfeiçoadas de higienização, a empresa utiliza nanotecnologia para ser líder em seu mercado atuante.

\section{RESULTADOS E DISCUSSÕES}

Conforme a avaliação de desempenho desenvolvida por meio do diagnóstico organizacional, tornou-se possível compreender a real situação das instituições. Deste modo, verificou-se o que necessitava ser alcançado e quais caminhos deveriam ser seguidos para com maior destreza atingir-se as metas e objetivos outrora estabelecidos. Basicamente, estas funcionaram como reguladoras do percurso específico, apontando quais ajustes deveriam ser realizados para concluir o que se deseja.

Conforme os estudos realizados na Imperlave Comércio e Serviços de Móveis EIRELLI, identificou-se quais eram os pontos fortes e os que necessitavam de melhorias. Cada área da organização é considerada de suma importância, fundamental ao seu sucesso institucional, conforme se evidencia a seguir na descrição de áreas no Gráfico 01: Média - Desempenho por Área Funcional. 
Gráfico 01 - Média - Desempenho por Área Funcional

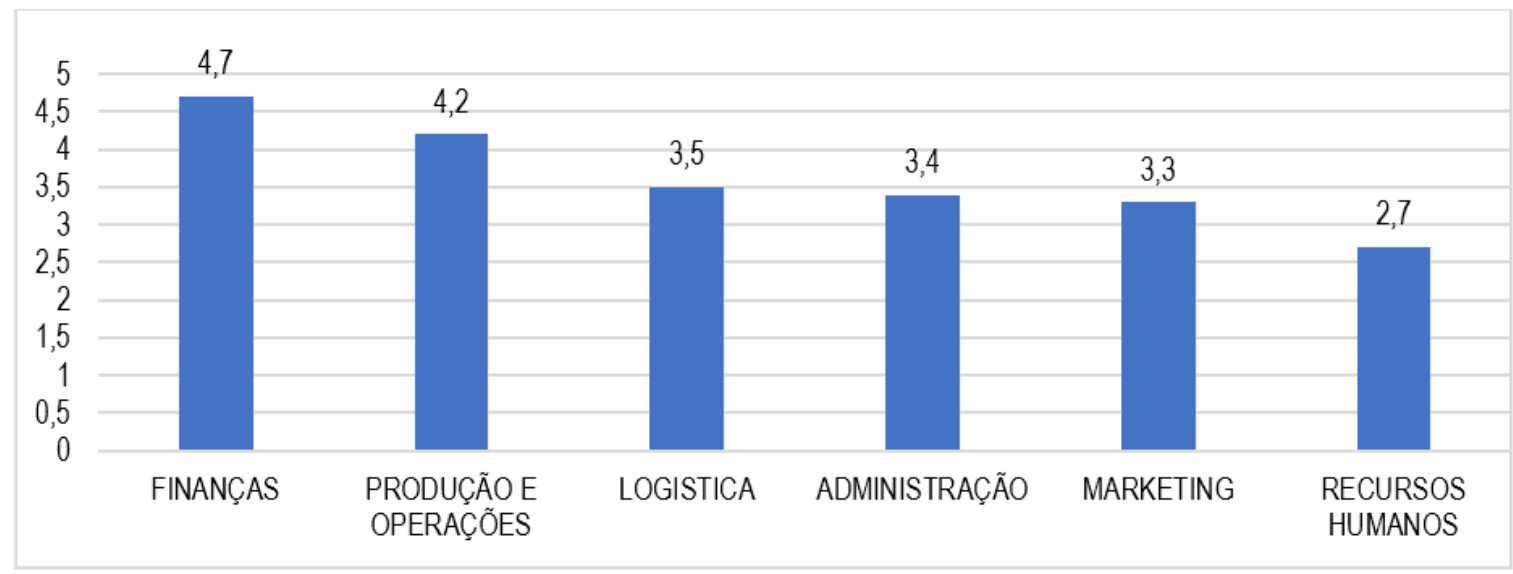

Segundo o abordado no gráfico 01, pôde-se verificar que a instituição Imperlave agregava valor às áreas de Finanças e Produção, como às mais bem avaliadas da corporação, sendo elas a de melhor desempenho, com média 4,7 e 4,2, acompanhadas da Logística, Administração e Marketing, com 3,5; 3,4 e 3,3 classificando-se como áreas de médio desempenho; já o Recursos Humanos foi considerado o setor com a mais baixa classificação, pois contou com média 2,7, ou seja, bem abaixo dos demais setores. Sendo assim, este era o que mais necessitava de desenlace para melhor fluidez e desenvolvimento interno.

Quadro 01 - Recursos Humanos

\begin{tabular}{|c|c|c|c|c|c|c|}
\hline \multirow{2}{*}{\multicolumn{2}{|c|}{$\begin{array}{l}\text { ÁREA FUNCIONAL } \\
\text { RECURSOS HUMANOS }\end{array}$}} & \multicolumn{5}{|c|}{ NÍVEL OU GRAU DE AVALIAÇÃO } \\
\hline & & Ponto & Ponto & Ponto & Ponto & Ponto \\
\hline 1 & $\begin{array}{llll}\text { Prioriza-se } 0 & \text { investimento } & \text { na } \\
\text { capacitação da } & \text { equipe } & \text { de } \\
\text { colaboradores. } & & & \\
& & \end{array}$ & & & $x$ & & \\
\hline
\end{tabular}




\begin{tabular}{|c|c|c|c|c|c|c|}
\hline 2 & $\begin{array}{l}\text { Registra-se um quadro funcional } \\
\text { legalizado nos padrões da CLT. }\end{array}$ & $x$ & & & & \\
\hline 3 & $\begin{array}{l}\text { Observa-se correto investimento em } \\
\text { equipamentos de proteção. }\end{array}$ & & & & $x$ & \\
\hline 4 & $\begin{array}{l}\text { Evidenciam-se } \\
\text { organizacionais de incentivo } \\
\text { corporativo. }\end{array}$ & & & & $x$ & \\
\hline 5 & $\begin{array}{l}\text { Observam-se políticas de benefícios } \\
\text { como ferramenta de incentivo. }\end{array}$ & & & & $x$ & \\
\hline 6 & $\begin{array}{l}\text { Observa-se inserção de novos } \\
\text { conhecimentos e capacitação } \\
\text { intelectual. }\end{array}$ & & & & & $x$ \\
\hline 7 & $\begin{array}{l}\text { Percebe-se boa política salarial, } \\
\text { benefícios, higiene e segurança } \\
\text { interna. }\end{array}$ & & $x$ & & & \\
\hline 8 & $\begin{array}{l}\text { Analisa-se a produtividade individual } \\
\text { dos técnicos. }\end{array}$ & & $x$ & & & \\
\hline 9 & $\begin{array}{l}\text { Nota-se preocupação com a saúde } \\
\text { ocupacional dos colaboradores. }\end{array}$ & & & & & $x$ \\
\hline 10 & $\begin{array}{l}\text { Compreende-se que todos são } \\
\text { responsáveis pelos resultados. }\end{array}$ & & & $x$ & & \\
\hline \multicolumn{2}{|c|}{ TOTAL $(\Sigma)$} & 5 & 8 & 6 & 6 & 2 \\
\hline \multicolumn{2}{|r|}{ MÉDIA POR GRAU (POR COLUNA) } & 0,5 & 0,8 & 0,6 & 0,6 & 0,2 \\
\hline \multicolumn{2}{|c|}{ DESEMPENHO DA ÁREA } & \multicolumn{5}{|l|}{2,7} \\
\hline
\end{tabular}

Fonte: Elaborado pelas autoras do diagnóstico mediante questionário aplicado, 2021

Constatou-se, segundo os dados apontados no Quadro 01, referentes aos Recursos Humanos da Imperlave, a evidência do grande número de pontos fracos e muito fracos. Dentre eles, destacaram-se: o desinteresse pela capacitação e saúde dos colaboradores e a falta de investimentos em EPI. Tais itens destacaram a severa necessidade de intervenções, de modo que, sensatamente, contando com o fácil 
desenvolvimento, a instituição alcançou com facilidade os resultados esperados em cada processo desenvolvido internamente. Sendo assim, a problemática abordada deseja compreender: Como a implementação do programa 8s na empresa Imperlave pode contribuir com as melhorias contínuas na área de recursos humanos?

\subsection{PLANEJAMENTO DE AÇÕES}

Demonstra-se a seguir uma tabela desenvolvida com o intuito de agregar métodos voltados ao aperfeiçoamento na organização objeto deste estudo. Nesta, propõemse atividades de fácil desenvolvimento que, alocadas adequadamente na organização, puderam acrescentar um grande diferencial nos serviços desenvolvidos e na qualidade do atendimento ao público, fomentando um novo aspecto visual na empresa, despertando o interesse daqueles que utilizam de seus produtos e serviços.

Quadro 02 - Ações interventivas

\begin{tabular}{|l|l|l|l|l|}
\hline $\mathbf{A c ̧ a ̃ e s ~ I n t e r v e n t i v a s ~}$ & Cronologia & Duração & Custo \\
\hline $\begin{array}{l}\text { Estruturar um plano de } \\
\text { treinamento voltado as } \\
\text { técnicas de padronização } \\
\text { de nível de serviço } \\
\text { pautado pelo 8S. }\end{array}$ & 15 dias & $\mathrm{R} \$ 2.000,00$ \\
\hline $\mathbf{2}$ & $\begin{array}{l}\text { Desenvolver programa de } \\
\text { redução e otimização dos } \\
\text { custos operacionais. }\end{array}$ & setembro/2021 & 30 dias & $\mathrm{R} \$ 1.700,00$ \\
\hline $\mathbf{3}$ & $\begin{array}{l}\text { Conscientizar as equipes } \\
\text { sobre os objetivos } \\
\text { estratégicos pautados nos } \\
\text { valores da organização. }\end{array}$ & agosto/2021 & Permanente & $\mathrm{R} \$ 2.000,00$ \\
\hline $\mathbf{4}$ & $\begin{array}{l}\text { Padronizar uniformes } \\
\text { para equipes de }\end{array}$ & setembro/2021 & 30 dias & $\mathrm{R} \$ 1.500,00$ \\
\hline
\end{tabular}




\begin{tabular}{|c|c|c|c|c|}
\hline & atendimento aos clientes. & & & \\
\hline 5 & $\begin{array}{l}\text { Criar programa de } \\
\text { incentivo premiado ao } \\
\text { processo de melhoria } \\
\text { contínua através da } \\
\text { introdução de programas } \\
\text { de Kaizen. }\end{array}$ & novembro/2021 & Permanente & $\begin{array}{l}\text { Gratificação } \\
\text { condicionada ao } \\
\text { resultado da } \\
\text { ação. }\end{array}$ \\
\hline 6 & $\begin{array}{l}\text { Consolidar a } \\
\text { implementação do projeto } \\
8 \mathrm{~S}\end{array}$ & $\begin{array}{l}\text { A partir de } \\
\text { agosto/2021 } \\
\text { (Atividade } \\
\text { permanente) }\end{array}$ & Seis Meses & $\begin{array}{l}\mathrm{R} \$ 5000,00 \text { no } \\
\text { período }\end{array}$ \\
\hline
\end{tabular}

Total

$\mathrm{R} \$ 7.200,00$

Fonte: Elaborado pelas autoras do diagnóstico mediante questionário aplicado, 2021

Conforme os dados acima, foi possível compreender quais atividades propostas eram viáveis à melhoria dos serviços em questão. Considerou-se que, agregando tais métodos, a total satisfação do cliente seria viável, tornando-se mais palpável e evidente, de modo que o cliente se tornou fiel e recomendou a instituição.

\subsubsection{FERRAMENTA DA QUALIDADE PARA IMPLEMENTAÇÃO $5 \mathrm{~W} 2 \mathrm{H}$}

Com a globalização, cada vez mais se tornou necessário inovar e atualizar as ferramentas empresariais. Neste sentido, foi desenvolvida a metodologia dos $5 \mathrm{~W} 2 \mathrm{H}$. Foi elaborada por grandes conhecedores e atuantes da indústria automotiva japonesa que necessitavam implementar um método capaz de orientar a ferramenta de PDCA, de modo que estes desenvolveram um conjunto de ações que evidenciaram todas as atividades internas essenciais, facilitando, assim, a detecção de falhas e de processos desnecessários. De acordo com Araújo (2017), destaca-se que é preciso responder quanto ao: o quê, por quê, quando, onde, quem, como e quanto custa. As respostas são de primordial necessidade para compreender quais 
as carências internas e, consequentemente, quais ações devem ser tomadas para resolução de tais problemas.

\subsubsection{ESTRUTURAR UM PLANO DE TREINAMENTO VOLTADO ÀS TÉCNICAS DE PADRONIZAÇÃO DE NÍVEL DE SERVIÇO PAUTADO PELO 8S (5W2H)}

Averiguou-se nos estudos in loco que a instituição carecia fortemente de treinamentos específicos voltados às técnicas de padronização. Neste quesito, a ferramenta 8s mostrou-se a mais adequada a demonstrar com clareza, tanto aos colaboradores quanto aos clientes, que a instituição possuía o foco em oferecer o melhor produto, com máximo benefício. A empresa possuía um quadro funcional bem formulado. No entanto, necessitava agregar mais cautela com o bem-estar e com os conhecimentos do seu capital humano. Estes deveriam compreender sua importância para a organização e a necessidade de atribuírem qualidade no atendimento ao público. Conforme o quadro 3, visualiza-se os métodos utilizados para inserção do treinamento desenvolvido por meio da metodologia $8 \mathrm{~s}$ na Imperlave.

Quadro 03 - Estruturar um plano de treinamento voltado a técnicas de padronização de nível de serviço pautado pelo 85

Estruturar um plano de treinamento voltado às técnicas de padronização de nível de serviço pautado pelo $8 \mathrm{~S}$

\begin{tabular}{|l|l|l|}
\hline What & O quê? & Treinar e introduzir o conceito na empresa. \\
\hline Why & Por quê? & Para padronização contínua. \\
\hline Where & Onde? & No setor produtivo da empresa. \\
\hline When & Quando? & Primeira semana de agosto de 2021. \\
\hline Who & Quem? & Setor de Recursos Humanos. \\
\hline How & Como? & $\begin{array}{l}\text { Criar plano de ação embasado em técnicas orientadas por } \\
\text { profissional externo especializado na área. }\end{array}$ \\
\hline How & Quanto? & $\mathrm{R} \$ 2.000,00$ \\
\hline
\end{tabular}




\section{Much}

Fonte: Autores, 2021

Segundo o quadro 03, introduziu-se o conceito no espaço de produção (por conta de ser a maior área da empresa) delimitado no mês de agosto/2021. O setor de Recursos Humanos desenvolveu e colocou em prática o plano de ação, para, na sequência, transmiti-lo aos demais colaboradores.

\subsubsection{DESENVOLVER PROGRAMA DE REDUÇÃO E OTIMIZAÇÃO DOS CUSTOS OPERACIONAIS (5W2H)}

Geralmente, quando se busca métodos para redução de custos, normalmente, compreende-se redução de gastos e pessoal, no entanto, existem outras maneiras que têm sido empregadas nos últimos tempos e têm se mostrado muito eficientes. Uma alternativa com menos impacto no ramo de otimização é a redução de desperdícios. Isto ocorre ao mapear-se as atividades em busca de gargalos. Esta ferramenta tem se traduzido no aumento da eficiência e da produtividade.

Quadro 04 - Desenvolver programa de redução e otimização dos custos operacionais

\begin{tabular}{|l|l|l|l|}
\hline \multicolumn{3}{|l|}{ Desenvolver programa de redução e otimização dos custos operacionais } \\
\hline What & O quê? & Treinar equipe e introduzir o conceito. \\
\hline Why & Por quê? & Para aumentar a produtividade e a eficiência reduzindo erros. \\
\hline Where & Onde? & Todos os setores da empresa. \\
\hline When & Quando? & Primeira semana de setembro de 2021. \\
\hline Who & Quem? & Departamento administrativo. \\
\hline How & Como? & $\begin{array}{l}\text { Efetuar investimento em software para sistema de gestão e } \\
\text { em treinamento para utilização. }\end{array}$ \\
\hline How & Quanto? & $\mathrm{R} \$ 1.700,00$ \\
\hline Much & & \\
\hline
\end{tabular}


Fonte: Autores, 2021

Demonstra-se no quadro 04 o desenvolvimento de uma metodologia inovadora para redução de custos e aumento da produtividade. Esta ferramenta foi aplicada em todas as áreas da empresa na primeira semana de setembro/2021. O departamento administrativo inseriu a ação. Esperou-se com a introdução deste instrumento que a organização pudesse evoluir e tornar-se cada vez mais segura financeiramente.

\subsubsection{CONSCIENTIZAR AS EQUIPES SOBRE OS OBJETIVOS ESTRATÉGICOS PAUTADOS NOS VALORES DA ORGANIZAÇÃO $(5 \mathrm{~W} 2 \mathrm{H})$}

Abraçar a cultura da instituição quer dizer que os colaboradores estão alinhados aos objetivos internos. Deste modo, a equipe deve ser guiada pelos valores internos. Afinal, é muito mais complicado reeducar um colaborador a seguir o padrão que a instituição do que inseri-lo no quadro funcional sabendo que este possui certa semelhança em termos de valores e crenças internas.

Quadro 05 - Conscientizar as equipes sobre os objetivos estratégicos pautados nos valores

\begin{tabular}{|c|c|c|}
\hline \multicolumn{3}{|c|}{$\begin{array}{l}\text { Conscientizar as equipes sobre os objetivos estratégicos pautados nos } \\
\text { valores }\end{array}$} \\
\hline What & O quê? & Estimular a adoção dos valores internos. \\
\hline Why & Por quê? & Para conquista dos objetivos estratégicos. \\
\hline Where & Onde? & Todos os setores. \\
\hline When & Quando? & Quarta semana de agosto de 2021. \\
\hline Who & Quem? & Gestores e proprietários da empresa. \\
\hline How & Como? & $\begin{array}{l}\text { Ministrar palestras e minicursos que demonstre os benefícios } \\
\text { da adoção destes recursos. }\end{array}$ \\
\hline $\begin{array}{l}\text { How } \\
\text { Much }\end{array}$ & Quanto? & $R \$ 2.000,00$ \\
\hline
\end{tabular}


Fonte: Autores, 2021

Conforme o quadro 05, instaurou-se na Imperlave a firme conscientização dos valores que, unificados aos interesses dos colaboradores, realizam a concretização dos objetivos estratégicos. Sua aplicação ocorreu no início da quarta semana de agosto/2021. Os gestores e proprietários efetuaram-na para máximo impacto interno. Com esta proposta, todos abarcaram um mesmo desejo interno: o de realizar os objetivos e alcançar as metas estabelecidas com máximo aproveitamento.

\subsubsection{PADRONIZAR UNIFORMES PARA EQUIPES DE ATENDIMENTO AOS CLIENTES (5W2H)}

Estar uniformizado, mesmo que sem contato direto com o cliente final, demonstra que a empresa possui um maior nível de organização e seriedade, o que desenvolve a identidade da instituição e a distingue das demais. Uniformizar a organização transmite um ar de padronização e segurança a todos os stakeholders.

Quadro 06: Padronizar uniformes para equipes de atendimento aos clientes

\section{Padronizar uniformes para equipes de atendimento aos clientes}

\begin{tabular}{|l|l|l|}
\hline What & O quê? & Uniformizar todos os colaboradores. \\
\hline Why & Por quê? & Para padronizar e reduzir riscos de acidentes. \\
\hline Where & Onde? & Em toda organização. \\
\hline When & Quando? & Primeira semana de setembro de 2021. \\
\hline Who & Quem? & $\begin{array}{l}\text { O setor administrativo, através da contratação de empresa } \\
\text { especializada na fabricação de fardamentos para o setor. }\end{array}$ \\
\hline How & Como? & $\begin{array}{l}\text { Externamente, produção conforme as medidas corporais dos } \\
\text { colaboradores. }\end{array}$ \\
\hline How & Quanto? & $\mathrm{R} \$ 1.500,00$ \\
\hline Much & & \\
\hline
\end{tabular}

Fonte: Autores, 2021

RC: 102301

Disponível em: https://www.nucleodoconhecimento.com.br/administracao/metodo-8s 
Apresenta-se no quadro 06 a aplicação de um método viável ao aumento da padronização que garantiu inúmeras melhorias. O setor administrativo foi responsável por solicitar cotações e contratar a empresa que mais se encaixava no saneamento das necessidades e capacidades internas. O desenvolvimento desta ação se deu no início da primeira semana de setembro/2021. Com a inserção do padrão de vestimenta, e este seguido à risca, houve uma maior segurança transmitida pelos colaboradores, melhora no contato com o público, além destes terem transmitido o visual da instituição, a sua identidade.

\subsubsection{CRIAR PROGRAMA DE INCENTIVO PREMIADO AO PROCESSO DE MELHORIA CONTÍNUA ATRAVÉS DA INTRODUÇÃO DE PROGRAMAS DE KAIZEN (5W2H)}

A metodologia Kaizen tem como base reduzir custos e aumentar a produtividade. Deste modo, tendo em vista que constantemente a sociedade se modifica e se atualiza, a empresa deve melhorar constantemente suas atividades e adaptar-se à competitividade rotineira. Estabelecer o conceito de que os colaboradores são os bens mais preciosos da instituição é o principal modo de incentivá-los e guiá-los ao desenvolvimento das atividades, de modo que esses colaboradores devem se concentrar na concretização das metas.

Quadro 07 - Criar programa de incentivo premiado ao processo de melhoria contínua através da introdução de programas de kaizen

Criar programa de incentivo premiado ao processo de melhoria contínua através da introdução de programas de Kaizen

\begin{tabular}{|l|l|l|l|}
\hline What & O quê? & Incentivar os colaboradores. \\
\hline Why & Por quê? & Para redução efetiva de custos e aumento da motivação. \\
\hline Where & Onde? & Todos os setores. \\
\hline When & Quando? & Primeira semana de novembro de 2021. \\
\hline Who & Quem? & Setores de Recursos Humanos, Administrativo e Compras. \\
\hline How & Como? & Elaboração de metas semestrais para realização, o colaborador \\
\hline
\end{tabular}


que as atingir e destacar-se dos demais conquistará uma premiação física ou um vale-presente para bonificação, sempre atendendo as leis trabalhistas. Além desta ação, o setor administrativo cotará e as compras efetuarão a aquisição de planos de saúde e odontológicos a todos.

How Quanto? Gratificação condicionada ao resultado da ação.

Much

Fonte: Autores, 2021

Segundo o quadro 07, a ação proposta envolveu a inserção de incentivos por meio de premiações e bonificações ao funcionário que realizasse as metas e mais se destacassem frente aos demais. Outra ação proposta é a inserção de planos de saúde e odontológicos a todos os colaboradores. As atividades foram gerenciadas e colocadas em prática na primeira semana de novembro/2021. Desejava-se com essas ações motivar os colaboradores e incentivá-los a continuar na instituição e a evoluir com ela, conquistando melhorias pessoais e transformando a realidade da organização.

\subsubsection{CONSOLIDAR A IMPLEMENTAÇÃO DO PROJETO 8S (5W2H)}

A metodologia possui a intenção de mudar a cultura organizacional, sendo assim, apenas apresentá-la na empresa e não aderir técnicas de enraizamento, ou seja, colocá-la em prática, não é o suficiente para desenvolver disciplina e compreender quais são e onde estão as falhas.

Quadro 08: Consolidar a implementação do projeto 8s

Consolidar a implementação do projeto $8 \mathrm{~S}$

What O quê? Implementar os $8 \mathrm{~s}$ internamente.

Why Por quê? Para inserir o conceito e treinar os colaboradores a segui-los.

Where Onde? Todos os setores. 
When Quando? A partir da segunda semana de agosto de 2021.

Who Quem? Gestores e proprietários da empresa.

Instaurar o chamado "Dia D" abordado no plano de ações e a

How Como? cada período estabelecido ministrar palestras e minicursos que demonstrem os benefícios da adoção destes recursos.

How

Much

Quanto? $\mathrm{R} \$ 5.000,00$ para todo o período.

Fonte: Autores, 2021

Apresenta-se no quadro 08 a proposta que teve como intuito de fortalecer a ferramenta interna que possuía foco não somente nos desejos da empresa, mas também conseguiu envolver os colaboradores e valorizá-los. Incutiu-se aos gestores e proprietários o dever de inserir as práticas a partir da segunda semana de agosto/2021.

\section{CONSIDERAÇÕES FINAIS}

No presente estudo, verificou-se as áreas funcionais da empresa Imperlave Comércio e Serviços de Móveis - EIRELLI, instituição esta que, por meio do Diagnóstico Organizacional, abordou os Recursos Humanos como a mínima classe englobada por problemas que, por sua vez, possuem simples resoluções. O objetivo geral visou delinear a efetivação do método $8 S$ na gestão de Recursos Humanos da empresa, em sequência, os específicos foram: detalhar a metodologia e seus benefícios a gestão organizacional; analisar os processos que podem ser submetidos a esta; e introduzir os resultados obtidos por meio do método. A abordagem e inserção destes objetivos foram empregadas no decorrer da Fundamentação Teórica, de modo que, com nitidez e seriedade, os tópicos foram referenciados sistematicamente, conforme as bases estabelecidas nas ações. A problemática da pesquisa pretendeu compreender: Como a implementação do programa $8 \mathrm{~S}$ na empresa Imperlave pode contribuir com as melhorias contínuas na área de recursos humanos? Este questionamento tornou-se deliberado quando, por 
meio da ferramenta $5 \mathrm{~W} 2 \mathrm{H}$, aplicou-se a estruturação de um plano de treinamento pautado em técnicas de 8S. A consolidação interna destes conceitos proporcionou benefícios relativos ao bem-estar das equipes, incentivando a criatividade, engajamento das equipes, qualidade de vida no trabalho e, por conseguinte, maior motivação dos colaboradores. Desde os primórdios de seu desenvolvimento como ciência, os Recursos Humanos buscam atrelar valores ao corpo colaborativo das instituições, no entanto, na instituição foco deste estudo, este foco inexistia. Erros como: a falta de investimento em equipamentos de proteção, falta de políticas organizacionais de benefícios e incentivos corporativos, além do zelo pela capacitação e saúde ocupacional dos colaboradores, foram os mais destacados.

Contudo, a reflexão desenvolvida nos ambientes organizacionais desdobrou-se por meios qualitativos, exploratórios e bibliográficos e tornou possível a adesão aos corretos métodos de conduta com os clientes. Aponta-se contribuições na padronização e na produtividade; já os incentivos e treinamentos incorporam valor aos demais setores da organização, o que, por sua vez, impulsiona o crescimento ao capital. Sendo assim, todos os resultados desejados foram atendidos e o aprimoramento na organização foi visivelmente evidente. Conclui-se que gerenciar pessoas na atualidade é umas das atividades de maior dificuldade que pode existir nas corporações, isto por lidar especificamente com capital humano, indivíduos que possuem seus próprios preceitos, ideais e conjunto de crenças. No entanto, o gestor de recursos humanos deve manter-se empenhado em produzir o melhor ambiente organizacional possível, aprimorando a conexão entre a corporação e o colaborador.

\section{REFERÊNCIAS}

ARAÚJO, A. L. S. de. Gestão da qualidade: implantação das ferramentas $5 \mathrm{~s}$ e 5w2h como plano de ação no setor de oficina em uma empresa de automóveis na cidade de João Pessoa - PB. 2017. 57f. Trabalho de Conclusão de Curso (Bacharel em Engenharia de Produção Mecânica) - Universidade Federal da Paraíba, João Pessoa, PB, 2017. 
BEDANI, M. O impacto dos valores organizacionais na percepção de estímulos e barreiras à criatividade no ambiente de trabalho. RAM Revista de Administração Mackenzie, v. 13, n. 3, p. 150-176, 2012.

CARDOSO, L. Práticas de gestão de recursos humanos e desempenho organizacional. Lisboa: ISPA - Instituto Universitário de Ciências Psicológicas, Sociais e da Vida, 2012.

CASARIN, N. Disseminação de práticas lean em armazéns de matérias-primas utilizando kaizen. 2012. 143f. Dissertação (Mestrado em Engenharia de Produção) - Universidade Federal de Santa Catarina, Florianópolis, SC, 2012.

CHIAVENATO, I. Gestão de pessoas: o novo papel dos recursos humanos nas organizações. 4를. ed. São Paulo: Manole, 2014.

FEIJÓ, R. P.; BEHR, A. Alternativa para redução de custos com o uso da análise da viabilidade da internalização de serviços secundários: estudo de caso em uma concessionária de veículos. 2016. 25f. Artigo (Bacharel em Ciências Contábeis) - Universidade Federal do Rio Grande do Sul, Porto Alegre, RS, 2016.

FERREIRA, Aline da Silva. Estudo para implantação do programa 8 s no setor de arquivo municipal: o caso da prefeitura de Paranavaí. ROCA: Repositório de Outras Coleções abertas - Pato Branco: Universidade Tecnológica Federal do Paraná, 2013.

FERREIRA, A. V. S. Elementos de articulação: missão, visão, valores e a identidade organizacional. Revista Eduicep, v. 1, n. 1, p. 33-52, 2016.

GARCIA, E. Pesquisa bibliográfica versus revisão bibliográfica-uma discussão necessária. Línguas \& Letras, v. 17, n. 35, p. 291-294, 2016.

LOUREIRO, A. M. M. O método kaizen aplicado na farmácia de oficina. 2018. 55f. Dissertação (Mestrado Integrado em Ciências Farmacêuticas) - Universidade de Coimbra, Coimbra, Portugal, 2018. 
DIAS, G. T. de. M. et al. O aprimoramento do método segundo os princípios de Kaizen e suas limitações. Sistemas \& Gestão, v. 15, n. 3, p. 199-200, 2020.

MIZDAL, R. H. Aplicação da ferramenta 5s no setor de manutenção automotiva. 2017. 34f. Monografia (Pós-Graduação Lato Sensu em Engenharia Industrial) Universidade Regional do Noroeste do estado do Rio Grande do Sul - UNIJUí, Panambi, RS, 2017.

PRAÇA, F. S. G. Metodologia da pesquisa científica: organização estrutural e os desafios para redigir o trabalho de conclusão. Revista Eletrônica "Diálogos Acadêmicos, v. 8, n. 1, p. 72-87, 2015.

PROETTI, S. As pesquisas qualitativa e quantitativa como métodos de investigação científica: Um estudo comparativo e objetivo. Revista Lumen, v. 2, n. 4, 2018.

REIS, J. M. et al. A inovação tecnológica como elemento de redução de custos na administração pública. In: Encontro de Gestão e Negócios - EGEN, 2018.

SANTOS, F. H.; DEMAMBRO, E. A rotatividade de pessoal nas organizações: a importância da gestão de Recursos humanos na cultura organizacional. Barra do Garças: Instituto Federal de Educação, Ciência e Tecnologia de Mato Grosso IFMT, 2021.

SEVERINO, A. J. Metodologia do trabalho científico. $1^{\underline{a}}$ ed. São Paulo: Cortez, 2013.

SILVA, K. F. da.; FERNANDES, V. L. N. A.; DANDARO, F. Motivação como aumento da satisfação e melhoria de desempenho na empresa de materiais rodantes. Revista Eletrônica "Diálogos Acadêmicos, v. 4, n. 1, p. 23-45, 2013.

SIMONI, S. Padronização do processo de atendimento nas ginásticas em grupo. Revista Carioca de Educação Física, v. 11, p. 25-33, 2016. 
SOUZA, K. R.; KERBAUY, M. T. M. Abordagem quanti-qualitativa: superação da dicotoamia quantitativa-qualitativa na pesquisa em educação. Educação e Filosofia, v. 31, n. 61, p. 21-44, 2017.

CARVALHO, M. B. et al. O papel dos benefícios e incentivos na satisfação do colaborador e nas estratégias das empresas. Caderno de Graduação-Ciências Humanas e Sociais-UNIT-SERGIPE, v. 1, n. 3, p. 31-44, 2013.

TANAKA, W. Y.; MUNIZ JR, J.; FARIA NETO, A. Fatores críticos para implantação de projetos de melhoria contínua segundo líderes e consultores industriais. Sistemas \& Gestão, v. 7, n. 1, p. 103-121, 2012.

TEIXEIRA, P. C. et al. Padronização e melhoria de processos produtivos em empresas de panificação: estudo de múltiplos casos. Production, v. 24, p. 311-321, 2014.

TERRA, L.; LIBÓRIO, D. Metodologia cientifica. São Paulo: Rede Internacional de Universidades Laureate, 2015.

VERAS, G. et al. Qualidade no atendimento ao cliente. In: XIV Jornada de Iniciação Científica - X Semana de Extensão, 2012.

VIEIRA, A. M. et al. Diretrizes para desenvolvimento coletivo de melhoria contínua em arranjos produtivos locais. Gestão \& Produção, v. 20, p. 469-480, 2013.

Enviado: Outubro, 2021.

Aprovado: Novembro, 2021. 